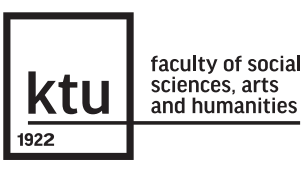

SAL 38/2021

Research Journal Studies about Languages pp. 81-98

ISSN 1648-2824 (print)

ISSN 2029-7203 (online)

DOI 10.5755/j01.sal.1.38.27575
LINGUISTICS / KALBOTYRA

Coronapandemie-Wortschatz im Gegenwartsdeutschen und Gegenwartsukrainischen

Received 09/2020

Accepted 02/2021

crossef http://dx.doi.org/10.5755/j01.sal.1.38.27575

HOW TO CITE: Kovbasyuk, L. (2021). Coronapandemie-Wortschatz im Gegenwartsdeutschen und Gegenwartsukrainischen. Studies about Languages / Kalbu studijos 38, 81-98. http://doi.org/10.5755/j01.sal.1.38.27575

\title{
Coronapandemie-Wortschatz im Gegenwartsdeutschen und Gegenwartsukrainischen
}

\section{Koronaviruso žodynas šiuolaikinẻse vokiečių ir ukrainiečiu kalbose}

\author{
LARYSA KOVBASYUK, Kherson State University, Ukraine
}

\begin{abstract}
In diesem Beitrag werden Ergebnisse zur kontrastiven Forschung zum Coronapandemie-Wortschatz im Gegenwartsdeutschen und Gegenwartsukrainischen vorgestellt. Das Ziel dieses Beitrags besteht darin, die Wörter, die in der Corona-Zeit in Deutschland und in der Ukraine verwendet werden, zu berücksichtigen, die strukturell-semantischen Merkmale von ausgewählten Wörtern in beiden Sprachen zu beschreiben, eine konzeptuelle Analyse durchzuführen, Wortpaare kontrastiv zu untersuchen, vorhandene Äquivalenztypen festzustellen und zu beschreiben. Die Analyse stützt sich auf ein manuell zusammengestelltes Korpus zum Coronapandemie-Wortschatz (deutsch: 735 Wörter / ukrainisch: 235 Wörter), wobei festzuhalten ist, dass die Menge der Einheiten des Korpus in beiden Sprachen variiert. Die gesammelten Wörter wurden in Sachgruppen eingeteilt, die quantitativ unterschiedlich repräsentiert sind. Die strukturell-semantischen Merkmale der Wörter des Korpus wurden beschrieben. Die Wortbildungstypen in beiden Sprachen wurden präzis dargestellt. Anhand des untersuchten Materials konnte ermittelt werden, dass die Anzahl der Entlehnungen und der Neubildungen in beiden Sprachen quantitativ differiert. Konzeptuelle Metaphern und Metonymien wurden ermittelt und beschrieben. Die Kontrastierung der deutsch-ukrainischen Wortpaare aufgrund der semantischen Übereinstimmungen und Unterschiede erlaubt es, von Voll-, Teil- und Nulläquivalenz zu sprechen.
\end{abstract}

SCHLÜSSELWÖRTER: kontrastive Analyse, Wort, Wortbildung, Neologismus, Metapher, Metonymie, Äquivalenz.

\section{Einführung}

Den Angaben der chinesischen Behörden zufolge ist der erste SARS-COVID-19-Fall bereits am 12. Dezember 2019 registriert worden. Am 11. Januar wird der erste Todesfall in China vermeldet. Mitte Januar 2020 werden erste Krankheitsfälle außerhalb Chinas bestätigt. Kurz vor dem chinesischen Neujahr stellen die Behörden zuerst Wuhan mit seinen elf Millionen Einwohnern unter Quarantäne, und später andere chinesische Städte. Das Coronavirus SARS-COV-2 beginnt, sich rund um den Globus auszubreiten (WHO, 2020).

Mitte März 2020 wird die Europäische Region der WHO zum Epizentrum der Pandemie. Den ersten Fall in Deutschland meldet das bayerische Gesundheitsministerium am 27. Januar (BMG, 2020). In der Ukraine wird der erste Fall am 3. März registriert (MGSU, 2020). 
Seit März 2020 befindet sich die ganze Welt in der Coronavirus-Pandemie, die das Leben der meisten Menschen in vielen Ländern extrem verändert hat. Grenzen werden geschlossen, Rückholaktionen organisiert, Strategien gegen die Ausbreitung des Coronavirus werden ausgearbeitet, Kontaktpersonen der Infizierten müssen identifiziert, untersucht und anschließend in häuslicher Quarantäne betreut werden, Therapien sowie Impfstoffe werden erforscht, Beschränkungen des sozialen Lebens werden eingeführt ect. Jeden Tag werden aktualisierte Informationen über die Anzahl der Coronavirus-Fälle in der Welt veröffentlicht.

Neue Wörter, Wortverbindungen und Wendungen, die auf das SARS-COV-2-Virus und die entsprechende Erkrankung COVID-19 referieren, sind aus dem alläglichen Sprachgebrauch in verschiedenen Diskursen sowohl in Deutschland als auch in der Ukraine nicht mehr wegzudenken. Deshalb sollte man diesen neuen sprachlichen Einheiten eine angemessene Aufmerksamkeit bei kontrastiven linguistischen Studien des Gegenwartsdeutschen und des Gegenwartsukrainischen schenken.

In diesem Beitrag werden die Ergebnisse einer Studie zum Coronavirus-Wortschatz im Deutschen und im Ukrainischen seit dem Ausbruch der Corona-Pandemie vorgestellt. Das Ziel dieses Beitrages besteht darin, Wörter, die in der Corona-Zeit in Deutschland und in der Ukraine verwendet werden, in einem Untersuchungskorpus zusammenzutragen, ihre strukturell-semantischen Merkmale in beiden Sprachen zu beschreiben, eine konzeptuelle Analyse durchzuführen, Wortpaare kontrastiv zu beschreiben und vorhandene Äquivalenztypen festzustellen und zu analysieren.

\section{Forschungsstand}

Der aktuelle Entwicklungsstand der Linguistik ist unseres Erachtens nach durch drei Hauptforschungstrends gekennzeichnet: 1) die Beschreibung ausgewählter Sprachen aus verschiedenen linguistischen Perspektiven, um Besonderheiten der nationalen und kulturellen Weltsicht festzustellen, 2) die vergleichende, diachronisch orientierte Erforschung der Sprachen und 3) kontrastive, synchronisch orientierte Studien verwandter und nicht verwandter Sprachen.

Die kontrastive Untersuchung verschiedener Sprachen ist ein sehr beliebtes Gebiet gegenwärtiger linguistischer Forschung. Dies kann sowohl durch die moderne Globalisierung als auch durch die Tatsache erklärt werden, dass die heutige Zeit eine Ära der interkulturellen Kommunikation ist. Die kontrastiven Studien sind Forschungsgegenstand der Kontrastiven Linguistik, die ihren Durchbruch in der zweiten Hälfte des 20. Jahrhunderts verzeichnet hat. Die kontrastive Linguistik ist stark im Strukturalismus der fünfziger Jahre verankert, der den Fremdsprachenunterricht auf eine neue Grundlage gestellt hat. Nach König und Nekula $(2013,5.15)$ hatte das Programm der Kontrastiven Linguistik das Ziel,

durch systematische Einbeziehung von Gemeinsamkeiten und Kontrasten zwischen Muttersprache und zu erlernender Fremdsprache, durch die damit verbundene Möglichkeit, Lernschwierigkeiten vorauszusagen und durch Lehrmaterial und Lehrstrategien, die auf diesen Erkenntnissen aufbauen, den Fremdsprachenunterricht effektiver zu gestalten. (König und Nekula, 2013, S. 15)

Heutzutage wird die kontrastive Linguistik als Zweig der vergleichenden Sprachwissenschaft angesehen, in deren Rahmen die allgemeinen und unterschiedlichen Mengen und Anzahl der Einheiten, aus denen ein bestimmtes sprachliches Teilsystem besteht, untersucht werden, die Besonderheiten der systemischen Organisation des Mikrosystems in den untersuchten Sprachen festgelegt und der Kern/die Peripherie der Teilsysteme in den vergleichenden Sprachen ermittelt werden (Sternin, 2006, S. 15).

Es ist zu betonen, dass Linguisten keine gemeinsame Sichtweise darüber haben, was die kontrastive Linguistik untersucht. Einige Sprachforscher meinen, dass sich die kontrastive Linguistik mit dem Vergleich zweier oder mehrerer Sprachen beschäftigt, um Gemeinsamkeiten und Unterschiede zwischen den Sprachen auf verschiedenen sprachlichen Ebenen festzustellen.

Die Kontrastive Linguistik als vergleichende sprachwissenschaftliche Methode hat ihren Schwerpunkt in der Ermittlung und Beschreibung von Gemeinsamkeiten, Ähnlichkeiten und Unterschieden zwischen zwei oder mehreren Sprachen. (Tekin, 2012, S. 9)

Andere Linguisten sind dagegen der Meinung, dass die kontrastive Linguistik nur zwei Sprachen, die Muttersprache und die Sprache, die gelernt wird, untersuche. Dabei werden nicht Subsysteme, semantische Felder 
und andere Struktureinheiten des lexikalischen Systems analysiert, sondern einzelne sprachliche Einheiten und Phänomene in zwei vergleichenden Sprachen. Die kontrastive Linguistik geht davon aus, dass sowohl eine Spracheinheit der Sprache A als auch alle ihr entsprechenden Spracheinheiten der Sprache B analysiert werden (Sternin, 2006, S. 24, 26; Gudavičius, 1985, S. 4).

Einen großen Beitrag für die interkulturelle Kommunikation und gleichzeitig für die Translationswissenschaft leisteten die kontrastive Lexikologie, die als 'Theorie und Praxis der Unterschiede und Gemeinsamkeiten der Strukturierungen im Wortschatz' definiert wird (Lutzeier, 1995, S. 7-19), und die kontrastive Semasiologie, die das lexikalische System einer Sprachen 'im Spiegel der anderen' Sprache untersucht. Somit umfasst die kontrastive Semasiologie zusammen mit der Lösung spezifischer Probleme der Vergleichsmethode selbst alle Probleme der deskriptiven Semasiologie einer bestimmten Sprache und die didaktischen Ziele beim Fremdsprachenunterricht, indem die Unterschiede zwischen den Sprachen gelernt werden (Gudavičius, 1985, S. 4).

Gegenwärtig besteht das neue Profil der Kontrastiven Linguistik aus folgenden Hauptpunkten (König und Nekula, 2013, S. 16-17):

1 die Studien sind synchronisch orientiert;

2 Kontraste zwischen den Sprachen werden beobachtet;

3 Sprachenpaare werden verglichen;

4 eine Sprache wird aus der Perspektive der anderen beschrieben;

5 als theoretischer Rahmen gelten Ansätze aus verschiedenen linguistischen Schulen und Richtungen;

6 das Ziel besteht in der Erarbeitung von Verallgemeinerungen über die Kontraste in Sprachpaaren.

Besonders richtungweisend sind seit Ende des 20. Jahrhunderts kontrastive Studien auf den Gebieten Lexikologie und Phraseologie, die eine lange Tradition sowohl in der ukrainischen als auch in der Germanistik im Allgemeinen haben. Die Ergebnisse dieser Studien wurden sowohl auf den internationalen Konferenzen 'Probleme der kontrastiven Semantik' an der Kyiv National Linguistic University als auch in der Zeitschrift Typologie sprachlicher Bedeutungen in diachroner und kontrastiver Hinsicht veröffentlicht. Zu erwähnen sind auch der Kongress Contrastive Phraseology: Languages and Cultures in Comparison in Mailand/Italien im November 2016 und die 2. Internationale Tagung zur Phraseologie und Parömiologie Deutsche Phraseologie und Parömiologie im Kontakt und im Kontrast in Wrocław/Polen im Mai 2019.

Jüngste Untersuchungen im Bereich der kontrastiven Linguistik richten sich auf grundlegende Fragen und allgemeine Perspektiven kontrastiver linguistischer Studien (Stutterheim, 2018) und auf die Analyse des Wortschatzes aus der Sicht der kognitiven Linguistik, indem kognitiv orientierte Methoden im Bereich der kontrastiven Phraseologie angewendet werden (Dobrovol'skij, 2018). Einen geeigneten Ausgangspunkt für weitere Forschung in der kontrastiven Linguistik bilden die Studie der Verschmelzung von Präposition und Artikel im Deutschen und Italienischen (Hagen, 2018) oder die Analyse von der Evolution des Etymons 'Wohnort' im Ukrainischen und Deutschen (Slavova, Borysenko und Kodubovska, 2020). Im Bereich der interkulturellen Kommunikation sind auch kontrastive Forschungen vorhanden, u. a. die Analyse der deutschen unoffiziellen Oykonyme (Kovbasyuk, 2019) und die kontrastive Analyse der exotischen Pluralformen im Englischen, Französischen, Italienischen und Ukrainischen (Pryimak, 2019).

Eine besondere Aufmerksamkeit verdienen unseres Erachtens die ukrainischen Studien aus der Perspektive der kontrastiven Linguokulturologie, die sich in der Ukraine im letzten Jahrzehnt intensiv entwickelt hat. Das große Interesse an diesem Thema beweisen die Studie über anthropozentrische Phraseologismen im Ukrainischen, Russischen, Polnischen und Englischen (Hryniuk, 2017), die korpusbasierte Untersuchung des linguokulterellen Konzepts SCHADENFREUDE im Englischen, Deutschen, Russischen und Ukrainischen (Mizin und Ovsiienko, 2020) etc.

Im Zentrum des Interesses dieser Studie liegt die kontrastive Forschung des Coronapandemie-Wortschatzes (Wörter) im Deutschen und Ukrainischen. Zur Sprache der Coronakrise existieren im Gegenwartsdeutschen schon zahlreiche Beiträge des Leibniz-Instituts für deutsche Sprache, u. a. eine sprachwissenschaftliche Betrachtung des Begriffs 'systemrelevant' (Möhrs, 2020) oder die schönsten Entdeckungen von Neologismen (Klosa-Kückelhaus, 2020). Sogar im Neologismenwörterbuch (NWB) wird der neu entstandene Corona-Wortschatz 
seit dem Ausbruch der Coronapandemie mit Belegen aus Print- und Onlinemedien dokumentiert (NWB, 2020). Im Ukrainischen ist diese Frage zur Zeit noch nicht thematisiert. Es fehlt nicht nur an linguistischen Aufsätzen über den Corona-Wortschatz, sondern auch an Arbeiten zur Aktualisierungen der ukrainischen Lexika und Wörterbücher in der Corona-Pandemie-Zeit. Neue Wörter kann man nur in Print- und Onlinemedien, in privaten Weblogs etc. finden.

Eine kontrastive Analyse erlaubt die Integration verschiedener Methoden der semantischen Methoden Analyse. Als methodologischer Rahmen unserer empirisch gestützten Studie gelten grundlegende, allgemeine wissenschaftliche und spezielle sprachliche Methoden, und zwar: induktive, deduktive und deskriptive Methoden, Methode der Wortbildungsanalyse (Konstituentenanalyse), kognitivlinguistische Analyse (konzeptuelle Analyse), Übersetzung, statistische Auswertung.

Die induktive Methode trägt zur Systematisierung und Beschreibung des Forschungsmaterials bei und ermöglicht gleichzeitig die Unterscheidung von Universalien bezogen auf das Korpus. Die deduktive Methode dient der Analyse, dem Vergleich und der Identifizierung gemeinsamer und charakteristischer Merkmale in beiden Sprachen. Die deskriptive Methode beinhaltet die Beschreibung der kontrastierten Wörter, die Zusammenstellung einer Liste des analysierten Materials aus ukrainischen und deutschen lexikografischen Quellen und erlaubt die Segmentierung, Klassifizierung und Interpretation des untersuchten Wortschatzes. Die Konstituentenanalyse bestimmt die Struktur der Wörter. Die kognitiv-linguistische Analyse ermöglicht die Feststellung semantischer Transformationen in den ausgewählten Sprachen. Die Übersetzung wird auch als operatives Mittel der Forschung verwendet, um semantisch-syntaktische Funktionsparameter und spezifische lexikalische Merkmale der vergleichbaren Kategorien in der Anfangsphase festzulegen. Die statistische Auswertung beruht auf Berechnungen des Anteils der Wörter (Wörterkonstituenten) am untersuchten Coronapandemie-Wortschatz.

Was die Methodik der kontrastiven lexikologischen Analysen angeht, haben wir uns in dieser Studie für den onomasiologischen Ansatz entschieden, indem nicht von den Einzelwörtern ausgegangen wird, um deren Bedeutungen aufzuführen, sondern von dem Konzept, um dafür Bezeichnungsmöglichkeiten zu suchen, da

Sprachen gleiche Inhalte auf unterschiedliche Weise zum Ausdruck bringen. [...] Sprachen unterscheiden sich auch darin, welche Gewichtung bestimmten begrifflichen Kategorien gegeben wird. (Stutterheim, 2020, S. 289)

Eines der Schlüsselkonzepte der kontrastiven Linguistik ist das Vergleichskriterium, das auf semantischer und grammatischer Ebene festgelegt wird oder als Äquivalenz-, Ähnlichkeits- und Unterschiedsverhältnis in den kontrastiv betrachteten Sprachen definiert wird. Bei der Ermittlung der Äquivalenzstufen werden Volläquivalenz (die Übereinstimmung der Wörter in allen Vergleichsparametern), Teiläquivalenz (Parallelität in einigen Merkmalen) und Nulläquivalenz (das absolute Fehlen von Entsprechungen) unterschieden (Chrissou, 2001, S. 141-155). Eine Voraussetzung für die kontrastive Untersuchung ist die Festlegung eines tertium comparationis, das als Vergleichsbasis gilt.

Die für unsere Studie ausgewählte komplexe Methodik soll in folgenden Schritten umgesetzt werden:

1 Definition des Coronapendemie-Wortschatzes.

2 Die Zusammenstellung des sprachlichen Materials im Deutschen und im Ukrainischen in einem Korpus, das SARS-COV-2 und COVID-19 repräsentiert.

Das deutsche Belegmaterial entstammt verschiedenen lexikografischen Quellen, z. B. dem Neologismenwörterbuch. Neuer Wortschatz rund um die Coronapandemie des Leibniz-Institutes für deutsche Sprache (NWB, 2020), dem Themenglossar zur COVID-19-Pandemie des Digitalen Wörterbuchs der deutschen Sprache (DWDS) (DWDS, 2020) und der Webseite des Bundesgesundheitsministeriums der BRD (BGM) (BGM, 2020). Das ukrainische Belegmaterial ist dem BBC.com (SEK, 2020) und dem Radiosvoboda.com (ST, 2020), die im Frühling 2020 diese kleinen Wörterbücher des Coronavirus zur Verfügung gestellt haben, dem Online-Wörterbuch des Gegenwartsukrainischen 'myslovo.com' (MS) (MS, 2020) und der Webseite des Ministeriums für Gesundheitsschutz der Ukraine (MGSU) (MGSU, 2020) entnommen. 
3 Die intralinguale Untersuchung der strukturellen und semantischen Merkmale des gesammelten Belegmaterials.

4 Die kontrastive Analyse des Materials.

Insgesamt enthält das Korpus 735 deutsche und 235 ukrainische Wörter zum Coronapandemie-Wortschatz.

Untersuchungsergebnisse

Definition des

Coronapandemie-

Wortschatzes
Unter dem Coronapandemie-Wortschatz verstehen wir den Wortschatz rund um die Coronavirus-Pandemie seit März 2020, der verstärkt im persönlichen Alltagsleben, im öffentlichen Verkehr, in unterschiedlichen Medien etc. verwendet wird.

Zu erwähnen ist, dass dieser Wortschatz im Deutschen und im Ukrainischen folgende grundlegenden Merkmale hat: 1) der Coronapandemie-

Wortschatz kann nach Sachgruppen gruppiert werden; 2) nach grammatischen Kriterien lassen sich die analysierten Wörter in unterschiedliche Wortarten ordnen, die sich in bestimmte Arten und Typen der Wortbildung einteilen lassen; 3) der Wortschatz kann in primäre (direkte) und sekundäre Nominationen (übertragene, semantisch transformierte) geteilt werden; 4) ein Teil des Wortschatzes ist entlehnt; 5) einige Benennungseinheiten existieren in den analysierten Sprachen seit langem, die anderen dagegen gelten als Neologismen es wird zwischen Allgemeinwortschatz und Fachwortschatz unterschieden, wobei letzterer vor allem im Gesundheitswesen gebraucht wird.

Das Coronavirus ist 'eine Infektionskrankheit, die durch das Virus SARS-CoV-2 (Severe acute respiratory syndrome-related coronavirus) verursacht ist' (NWB, 2020); 'Vertreter einer Familie verwandter Viren (Coronaviridae), die unterschiedlich schwere Infektionen der Atemwege verursachen' (DWDS, 2020). Im Ukrainischen wird zusätzlich darauf hingewiesen, dass das Virus aus China kommt: коронавірус 'пандемічна коронавірусна хвороба, що поширилася в усьому світі; була викликана новим штамом коронавірусу, що походить з міста Ухань у Китаї; родина вірусів, до якої належить вірус SARS-CoV-2' (SEK, 2020; ST, 2020). Diese Infektionskrankheit wird im Deutschen mit den Wörtern Corona, Coronavirus, Corönchen, COVID-19, SARS-CoV-2, im Ukrainischen mit корона, коронавірус, Ковід, ковідка, COVID-19, Sars-CoV-2 bezeichnet.

Die Coronapandemie (пандемія коронавірусу im Ukrainischen) ist 'der weltweite Ausbruch dieser Infektionskrankheit' (NWB, 2020).

Der Coronapandemie-Wortschatz im Gegenwartsdeutschen
Die Ergebnisse der Analyse des gesammelten Materials im Deutschen zeigen, dass der ausgewählte Wortschatz in folgende Sachgruppen gruppiert werden kann:

1 Gesundheitswesen.

1) Krankheit: Corona, Coronavirus, SARS-CoV-2, COVID-19, COVID-19-Fälle, COVID-19-Erkrankung, (Corona)Neuinfektion, Infektionszahlen, Infektionskette, Todesfälle, Wuhansyndrom.

2) Schutz und Schutzmaßnahmen: Abstandsgebot, Alltagsmaske, Beschränkungskonzept, Coronaabstand, Coronaregel, Coronarettungsschirm, Covid-19-Antikörpertest, Covidtest, Desinfektionsmittel, Distanzvorschrift, Einkaufswagenpflicht, Gesichtsschirm, Heimquarantäne, Hygieneregime, Impfstoffzulassung, Schutzausrüstung, Testpflicht, Teillockdown, Wechselmodell.

3) Infizierte Personen: Attackrate, Coronaer, Corona-Patient, COVID-19-Patient, der Infizierte, Superverbreiter, Kontaktperson, Multispreader.

4)Zeit: Corona-Krise, Corona-Zeit, Coronavirus-Chronik, präpandemisch, post-COVID-Zeit, Sommer-Ischgl.

2 Mensch:

1) Menschenbezeichnungen: a) nicht-infizierte Personen: Besuchstandem, Coronaimmuner, Coronials, Einkaufsheld, Coronamüder, Risikogruppe, Schnellshopper, Test-Urlauber; b) Personen, die nicht an Corona glauben: Aluhut, Coronaleugner, Coronaskeptiker, Coronasünder, Maskenmuffel.

2) emotionaler und psychischer Zustand: Coronablues, Coronahysterie, Coronaisolation, Covidiot, Isolationseinerlei, Tourismusphobie, Zoomfatigue. 
3) Körper: After-Corona-Body, Coronamähne, Coronakilo, Coronaspeck.

4) Erholung, Entspannung, Sport: Autokonzert, Coronahobby, Coronasommer, Coronaradweg, COVID-19-Party, Home-Coming-Garantie, Geisterspiel, Open-Air-Party, Piloturlauber, Wohnzimmer-Work-Out, Watchparty.

5) Essen: Geistergastronomie, Ghostkitchen, Krisenfutter, Quarantini.

6) Mode: Coronamode, Coronacouture, Coronafrisur, Maskenmode, Mundschutzmode, Trikini.

3 Soziales Leben.

1) Alltagsleben/Proteste Anticoronademonstration, Beherbergungsverbote, Coronafakeshop, Corona-Proteste, Coronaschock, Coronasoli, Gabenzaun, Hygienedemo, Kinderbonus, Onlinedemonstration.

2) Beschränkungen/Warnsysteme: Anderthalb-Meter-Gesellschaft, Appgesetz, Balkongesang, Besuchszone, Contaktracing, Coronaampelsystem, Corona-App, Corona-Prävention, Corona-Verhaltensregeln, CoronaWarn-App, Handytracking, Lockerung, Quarantäne, tracen, Warnapp.

3) Berufswelt: Anwesenheitskultur, Coronazuschuss, Coronasoforthilfe, Distanzarbeit, Homeworker, Kurzarbeit, Smartwork, Unterwegsreiniger, Videochat, Virusdetektiv.

4) Ausbildung: Coronajahrgang, Coronasemester, Draußenschule, Durchschnittsabitur, Geistervorlesung, Homeschooling, Outdoorklasse, Searvicelearning, Zoomschule.

5) Medien: Coronabulletin, Corona-Liveticker, Corona-Liveblog, Corona-Meldungen, Corona-Nachrichten, Corona-News, Coronatagebuch, WhatsApp-Infos.

6) Politik, Institutionen, Gremien: Coronakabinett, Krisenkanzlerin, Lockdowner, Paul-Ehrlich-Institut (PEI), RobertKoch-Institut (RKI), Verschwörungstheorie, Wumms.

Nach grammatischen Kategorien lassen sich die Coronapandemie-Wörter in vier Wortarten einteilen, die zu unterschiedlichen Wortbildungstypen gehören und sowohl primäre als auch sekundäre sprachliche Nominationen sind:

A. Substantive. Substantive bilden mit $86 \%$ die größte Gruppe. In der Gruppe werden einfache Wörter (8,8 \%), Zusammensetzungen (63,5\%), explizite Derivate (12,2\%), Konversionen (0,1\%) und Kurzwortbildungen (1,4\%) unterschieden.

1 Die Anzahl der einfachen Substantive ist gering, etwa 8,8\%. Einige Substantive (8,4 \%) sind entlehnt und sind sowohl primäre Nominationen, u. a. das Substantiv Chronik (griech.) 'Aufzeichnung von geschichtlichen Ereignissen größerer Zeiträume in zeitlich genauer Reihenfolge' (DWDS, 2020) als auch sekundäre Nominationen (vor allem konzeptuelle Metaphern), u. a. das Lexem Exit (engl.) 'Beendigung bzw. Ende eines bestimmten Zustandes, Ausstieg aus einer bestimmten Situation' (NWB, 2020), das die konzeptuelle Metapher AUSGANG IST ENDE repräsentiert.

Die anderen Benennungseinheiten sind Analogiebildungen $(0,4 \%)$ und gelten als primäre sprachliche Nominationen: Quarantini (in Analogie zu Martini) 'während der COVID-19-Pandemie eingeführter (und ggf. in Quarantäne genossener) Cocktail aus Gin, Wodka o. Ä., Limettensaft, Ingwerbier, Passionsfrucht u. a., garniert mit frischer Minze'; Trinkini (in Analogie zu Bikini) 'aus Badehose, Oberteil und (farblich passendem) Mundnasenschutz bestehende (knappe) Badebekleidung' (NWB, 2020).

2 Zusammensetzungen bilden die größte Gruppe. Zu betonen ist, dass folgende Wortkonstituenten in den nominalen Zusammensetzungen am häufigsten vertreten sind: Corona (20\%), COVID-19 (2\%), Abstand/ Distanz (1,4\%), Geister (1,2 \%), Viren/Virus (0,95\%), Covid/Immunitäts/Quarantäne (0,8 \%). Die ausgewählten Zusammensetzungen werden entweder zusammen oder durch Bindestrich, wenn eine der Konstituenten englischer Herkunft ist, geschrieben. In dieser Gruppe werden unterschieden:

1) Determinativkomposita (34\%) (deutsche, entlehnte Komposita oder Komposita mit entlehnten Konstituenten) mit direkter Bedeutung: Nomen-Nomen-Komposita ohne Fugenelement ( $21 \%)$ : Coronagruß 'während der COVID-19-Pandemie genutztes Zeichen des gegenseitigen Willkommenheißens zweier oder mehrerer Personen, die sich z. B. mit ihren Füßen berühren, statt sich die Hände zu schütteln', Risikogebiet 'Region oder Land mit einem erhöhten Risiko für die Gesundheit, die persönliche Sicherheit oder extreme Umweltereignisse' (DWDS, 2020); Adjektiv-Nomen-Komposita ohne Fugenelement (2 \%): Open-Air-Party 'Feier unter freiem Himmel'; Adverb-Nomen-Komposita ohne Fugenelement (1\%): Draußenschule '(Schul-) Unterricht, der außerhalb der dafür vorgesehenen Einrichtungen (unter freiem Himmel) stattfindet'; No- 
men-Nomen-Komposita mit Fugenelement (9\%): Abstandsregelung 'Verordnung bzw. Empfehlung während der COVID-19-Pandemie, in der Öffentlichkeit eine bestimmte Distanz zwischen zwei Personen einzuhalten' (NWB, 2020).

Zu dieser Gruppe gehören auch Komposita, die als eine Konstituente verschiedene Typen von Kurzwörtern haben (1,9\%):

a Kopfwörter (0,4 \%) (Kurzwörter, die aus dem Anfang seiner Langform bestehen), die meistens als zweite Konstituente verwendet werden: Coronasoli(darität) 'Sonderabgabe, die dabei helfen soll, Kosten wegen der COVID-19-Pandemie zu finanzieren', Coronakilo(gramm) 'durch Bewegungsmangel, Langeweile, Stress usw. während der COVID-19-Pandemie zugenommenes Körpergewicht' (NWB, 2020);

b Buchstabenwörter (1,2 \%), die überwiegend Initialwörter sind: AHA-Formel (Abstand + Hygiene + Alltagsmaske Regel) 'während der COVID-19-Pandemie empfohlene Abstands- und Hygieneregeln des deutschen Bundesgesundheitsministeriums', C-Wort (Corona-Wort) '(verhüllend für) Coronakrise'; R-Wert (Reproduktionszahl-Wert) 'die Zahl gibt an, wie viele weitere Menschen ein Infizierter im Schnitt ansteckt' (NWB, 2020);

c Silbenwörter (0,3\%), deren Silben nach Aussprechbarkeit geformt werden, häufig sind das die Idealsilben aus Konsonant + Vokal: Munaschu '(kurz für) Mundnasenschutz'; Munaske '(kurz für) Mundnasen(schutz)maske' (NWB, 2020).

2) deutsche Determinativkomposita, sekundäre Nominationen (28\%). Die Rede ist von konzeptuellen Metaphern, die mithilfe von Komposita gebildet werden. Das sind u. a. MENSCH IST EIN GEIST: Geistervorlesung 'Lehrveranstaltung (an einer Hochschule oder Universität), die mithilfe von Videokonferenzsystemen, Chatrooms, Onlinelernplattformen u. Ä. durchgeführt wird'; KRANKHEIT IST EIN KRIEG: Coronatestoffensive 'politisch angeordnete Aktion, bei der in einer Bevölkerung flächendeckend medizinische Untersuchungen zur Feststellung einer Infektion mit dem Coronavirus SARS-CoV-2 durchgeführt werden', Virusfront 'Infektionsgeschehen mit einem Virus, das (prognostiziert) einen Ort betreffen wird'; STUDIUM IST KREATIVITÄT: Kreativsemester 'akademisches Studienhalbjahr, das an die Ausgangs- und Alltagsbeschränkungen während der COVID-19-Pandemie angepasst ist'; VIDEOKONFERENZ IST EIN KRIEG: Zoomboombing 'böswillige Störung von Videokonferenzen (mit der Software Zoom ${ }^{\circledR}$ ) durch nicht zugelassene Nutzer'; TOURIST IST EIN PILOT: Piloturlauber 'Tourist, der nach Aufhebung der Reiseeinschränkungen während der COVID-19-Pandemie im Rahmen einer Testphase wieder eine Reise unternimmt' (NWB, 2020).

3) Bahuvrihi (0,1 \%) bzw. exozentrische Komposita nach Donalies E. (2005, S. 59) sekundäre Nominationen mit übertragener Bedeutung, u. a. das Wort Aluhut (Alu(miniumfolie)hut) 'Person, die an eine Verschwörungstheorie glaubt' (NWB, 2020). Die Anhänger von Verschwörungstheorien glauben, dass die aus Aluminiumfolie gestaltete Kopfbedeckung vor schädlichen Einflüssen auf das Gehirn schützen soll. In diesem Fall ist die Rede von einer konzeptuellen Metonymie mit dem kognitiven Metonymie-Modell: X STEHT FÜR Y: DER KOPFBEDECKUNG AUS ALUMINIUMFOLIE STEHT FÜR DEN MENSCHEN.

4) Wortverschmelzungen (oder auch Kontaminate) (1,4\%), die aus zwei ineinander verschachtelten Wörtern bestehen, sind in unserem Material selten vertreten. Morphologisch werden zwei Typen von Wortverschmelzungen unterschieden (Donalies, 2005, S. 89-90), die sekundäre Nominationen (konzeptuelle Metapher) sind: 1) Kontaminate, deren Konstituenten gemeinsame Laut/Buchstabenfolgen haben und die sich genau darin überschneiden: Coronamour (Corona + Amour) 'während der zur Eindämmung der COVID-19-Pandemie angeordneten Kontakt- und Alltagsbeschränkungen entstandene und durch diese geprägte Liebesbeziehung' (KRANKHEIT (CORONAVIRUS) REGT DIE LIEBE AN); Coronexit (Corona + Exit) 'Beendigung der gesellschaftlichen und wirtschaftlichen Beschränkungen während der COVID-19-Pandemie' (CORONABESCHRÄNKUNGEN SIND BEENDET); 2) Kontaminate, deren Komponenten keine gemeinsamen Lautfolgen haben und daher nach Kriterien der Aussprechbarkeit ineinander geschoben werden: Coronoia (Corona + Paranoia) 'irrational große Angst vor einer Ansteckung mit dem Coronavirus SARS-CoV-19' (KRANKHEIT (CORONAVIRUS) MACHT PARANOID); Panikdemie (Panik + Pandemie) 'sich rasch verbreitende, sehr große und lähmende Angst vor der COVID-19-Pandemie, die auch durch die von manchen als übertrieben kritisierte mediale Berichterstattung ausgelöst wird' (PANIK VERBREITET SICH RASCH UND MASSENHAFT) (NWB, 2020). 
3 Explizite Derivate werden in präfixale (8,2\%) und suffixale (4\%) Derivate geteilt.

1) Zu den präfixalen Derivaten ( $8 \%$ ) gehören Substanive sowohl mit den Fremdpräfixen anti- $(0,5 \%)$, multi- $(0,4$ $\%)$, post- $(0,9 \%)$, prä- $(0,8 \%)$, super- $(2,8 \%)$, die von Komposita bzw. von expliziten Derivaten gebildet werden.

Die meisten Derivate sind primäre Nominationen mit direkter Bedeutung: Anticoronaprotest '(politisch und weltanschaulich unterschiedlich motivierte) Kundgebung gegen die allgemein gültigen Verhaltensregeln zur Eindämmung der COVID-19-Pandemie'; Multiorganvirus 'viraler Krankheitserreger, der die Funktion mehrerer Körperorgane auf einmal beeinträchtigt'; Post-Corona-Zeit 'Zeitraum nach der durch das Coronavirus SARS-CoV-2 ausgelösten Pandemie (und ihren Folgen)'; Prä-Pandemie-Zeit 'Zeitraum vor der durch das Coronavirus SARSCoV-2 ausgelösten weltweiten Infektionswelle (und ihren Folgen)'; Superüberträger 'jemand, der eine ungewöhnlich hohe Anzahl anderer Menschen infiziert' (NBW, 2020).

2) Zu den Suffixderivaten (4 \%) gehören primäre Nominationen (meistens Entlehnungen) mit dem deutschen Suffix -er (3,8\%) oder mit dem Fremdsuffix -ial (0,2\%), das nur einmal für die Wortbildung gebraucht wird: Lockdowner 'Politiker, der besonders vehement die Stilllegung fast aller wirtschaftlichen und gesellschaftlichen Aktivitäten zu einem bestimmten Zeitraum während der COVID-19-Pandemie gefordert hat'; Coronials 'Teil einer Generation, die während der aufgrund der Ausbreitung von COVID-19 angeordneten Ausgangsbeschränkungen (in Heimquarantäne) gezeugt wurde' (NBW, 2020).

4 Konvertierungen. Als Wortbildungsprodukt dieser Wortbildungsart gilt nur ein vom Partizip II gebildetes Substantiv der Infizierte 'Mensch, der angesteckt ist' (0,1\%).

5 Kurzwortbildungen. Zu dieser Gruppe gehören Akronyme/Initialwörter (1,4 \%): RKI (Robert-Koch-Institut, die zentrale Einrichtung der Bundesregierung auf dem Gebiet der Krankheitsüberwachung und -prävention); WHO (Weltgesundheitsorganisation, im Deutschen wird das englische Akronym der World Health Organization gebraucht).

B. Adjektive bilden mit 7,5\% die zweitgrößte Gruppe unseres Untersuchungsmaterials. Alle Adjektive werden in zwei Gruppen geteilt: Zusammensetzungen (4,5\%) und explizite Derivate (3\%). Am häufigsten treten Corona $(0,3 \%)$ und Pandemie $(0,1 \%)$ als Konstituenten auf.

1 Die Zusammensetzungen (4,5\%) sind Nomen-Adjektiv-Komposita, primäre Nominationen: coronaadäquat 'den besonderen Umständen während der COVID-19-Pandemie entsprechend'; pandemiesicher 'den Hygienebestimmungen während der COVID-19-Pandemie genügend'; systemrelevant 'für die Teilhabe am gesellschaftlichen Leben innerhalb eines Systems bedeutsam' (NBW, 2020).

2 Explizite Derivate treten als suffixale (2\%) und präfixale (1\%) Derivate auf. Zu betonen ist, dass sie primäre Nominationen sind und dass als selbstständige Wörter am häufigsten Corona $(1,1 \%)$ und Pandemie $(0,7 \%)$ vorkommen.

1) Suffixale Derivate werden meistens mit den Suffixen -al (0,3\%), -ial (0,1\%), -esk (0,1\%), -frei (0,2 \%), -los (0,3 $\%)$, -isch (0,2 \%) gebildet, u. a. coronal 'die durch die COVID-19-Pandemie entstandene Krise betreffend, in ihr entstanden oder geltend'; coronistisch 'von der COVID-19-Pandemie zeugend'; maskenfrei '(trotz geltender Hygiene- und Abstandsregeln während der COVID-19-Pandemie) keinen Mund-Nasen-Schutz tragend' (NWB, 2020).

2) präfixale Derivate werden meistens mit den Präfixen multi- $(0,1 \%)$, post- $(0,4 \%)$ und prä- $(0,3 \%)$ gebildet: postpandemisch 'den Zeitraum nach der COVID-19-Pandemie betreffend, inn charakterisierend', präcoronal 'vor der durch das Coronavirus SARS-CoV-2 ausgelösten Pandemie (und ihren Folgen)'.

C. Die Partizipien I und II sind explizite Zusammensetzungen (3,5 \%).

Die Zusammensetzungen sind determinative Nomen-Verb-Komposita, primäre Nominationen. Als erste Konstituente kommen vor allem Entlehnungen Corona $(0,5 \%)$, Lockdown $(0,4 \%)$ und Pandemie $(0,34 \%)$ vor: coronageschädigt 'von (Maßnahmen während) der COVID-19-Pandemie (in hohem Maß) negativ betroffen'; pandemiebedingt 'hervorgerufen durch die besonderen Umstände während der COVID-19-Pandemie'.

Sekundäre Nominationen sind auch vorhanden, so ist z. B. die Rede von der englischen Entlehnung overzoomed 'durch zu viele Videokonferenzen (mit der Software Zoom ${ }^{\circledR}$ ) gestresst'. Es handelt sich um die sprachliche Repräsentation der konzeptuellen Metapher VIDEOKONFERENZ IST STRESS.

D. Die untersuchten Verben (3\%) sind explizite Derivate oder Komposita, die von den entlehnen Substantiven gebildet sind und am häufigsten zu den primären Nominationen gehören. 
1 Als Kompositum gilt das Nomen-Verb-Benennungseinheit: videochatten 'mithilfe softwareunterstützter digitaler Bild- und Tonübertragung miteinander kommunizieren' (NBW, 2020), mit einem Anteil von 0,1\% des Materials.

2 Explizite Derivate (2,9\%) sind mit Suffixen - $n(0,8 \%)$, -en (1\%), -ern (0,4\%), -ieren (0,7\%) gebildet, als Derivationsbasis gilt meistens Corona (0, 4\%): coronieren 'etwas den Bedingungen in Zeiten der COVID-19-Pandemie anpassen'; tracen '(digitale) Kontaktdaten von Personen (ohne Auswertung von Standortdaten) rückverfolgen'; zoomen '(digitale) Kontaktdaten von Personen (ohne Auswertung von Standortdaten) rückverfolgen' (NBW, 2020).

Als sekundäre Nomination kommt die konzeptuelle Metapher MENSCH IST EIN TIER vor: hamstern 'aus Angst vor Knappheit in Notsituationen möglichst große Vorräte der nötigsten Lebensmittel, Medikamente o. Ä. anlegen' (DWDS, 2020).

Die Untersuchung des Coronapandemie-Wortschatzes hat gezeigt, dass etwa $77 \%$ des untersuchten Materials Neologismen sind. Diese Neologismen lassen sich in folgende Typen unterscheiden:

1 Neubildungen oder Neulexeme fremder Herkunft mit metaphorischer Bedeutung (75 \%): Corontäne (Corona + Quarantäne) 'häusliche (Selbst-)Isolation während der COVID-19-Pandemie (KRANKHEIT (COVID-19) IST ISOLATION)'; Plandemie (Plan + Pandemie) '(nach verschwörungstheoretischer Überzeugung) die durch Politiker bewusst herbeigeführte COVID-19-Pandemie' (PLAN VERBREITET SICH RASCH UND MASSENHAFT); Staycation (stay (at home) + Vacation, engl.) 'Urlaub, der nicht in der Ferne, im Ausland o.Ä., sondern im eigenen Zuhause (und näherer Umgebung) verbracht wird' (HEIM IST URLAUBSORT) (NBW, 2020).

2 Neubedeutungen oder kodifizierte Formen mit einer neuen, metaphorischen Bedeutung (2\%). Im Material kommen folgende Lexeme vor: Epizentrum (griech.) 'akuter Mittelpunkt einer sich ausbreitenden Krankheit mit einer sehr hohen Anzahl betroffener Personen' (NBW, 2020). In der älteren Lesart 'der senkrecht über einem Erdbebenherd liegende Punkt auf der Erdoberfläche, an dem die Auswirkungen des Bebens oft am größten sind' (DWDS, 20020); Exit 'Beendigung bzw. Ende eines bestimmten Zustandes, Ausstieg aus einer bestimmten Situation' (NBW, 2020). In der älteren Lesart 'Ausgang, Notausgang' ist Exit ein Lehnwort aus dem Englischen (zu exit, '(der) Ausgang, (die) Ausfahrt, (das) Ende') (DWDS, 2020).

Im Coronapandemie-Wortschatz lassen sich auch Termini aus dem Medizinbereich finden. Der größte Teil dieser Termini, die etwa 5 \% des Materials bilden, sind Neologismen, die von A. Klosa-Kückelhaus (2020) nach Sachgruppen Anfang Sommer 2020 klassifiziert sind. Wir haben diese Klassifikation als Basis genommen, erweitert und vervollständigt, weil in den letzten drei Monaten einige neue Termini entstanden sind.

Die Belege lassen sich in folgende Sachgruppen einteilen:

1 Krankheit und Symptome: Corönchen, Covidhirn, COVID-19-Brain, Immunantwort, Wuhansyndrom.

2 Medizinische Einrichtungen: Coronaknast, Coronateststelle, Drive-in-Testzentrum, Quarantänehotel.

3 Methoden der Eindämmung des Virus: R-Wert-Ampel, Corona-Prävention, Corona-Verhaltensregeln, SAR-Wert.

4 Tests: Covid-19-Antikörpertest, Fast-Track-Test, PCR-Test.

5 Infizierte und nicht-infizierte Personen: Kontaktperson, Superverbreiter.

6 Ausbreitung und Behandlung: Ansteckungscluster, Coronaausbruch, COVID-Fall, 7-Tage-Inzidenz, Spreading, Triage.

Der Coronapandemie-Wortschatz im Gegenwartsukrainischen
Die Ergebnisse der Analyse des Belegmaterials im Ukrainischen zeigen, dass der ausgewählte Wortschatz wesentlich kleiner ist, weil Wortbildungen wie die Zusammensetzung im

Ukrainischen nicht so produktiv wie im Deutschen sind. Folgende Gruppen können unterschieden werden:

1 Gesundheitswesen:

1) Krankheit: антирекород, випадок, зараження, корона, коронавірус, коронавірусний, Ковід, ковідка, коронувати, повторний, реінфікування, спалах, COVID-19, Sars-CoV-2.

2) Schutz und Schutzmaßnahmen: антисептик, безконтактний, вакцина, дистанційний, госпіталізація, експрес-тест, захист, інкубація, ІФА-тест, карантин, карантинувати, локдаун, маска, обмежувальний, обсервація, онлайн-обстеження, противірусний, ПЛР-тест, самодіагностика, самоізоляція, санітайзер, скринінг, тампон-метод, тестування, чат-бот. 
3) Infizierte Personen: госпіталізований, заразний, інфікований, пацієнт, померлий, протестований, суперпоширювач, хворий.

4) Zeit: коронакриза, тимчасовий.

2 Mensch:

1) Menschenbezeichnungen: a) nicht-infizierte Pesonen: зумбі, карантьє, ковіденята, контактний, короніал, c) Personen, die nicht an Corona glauben: адепт, ковід-дисидент, коронадисидент.

2) Emotionaler und psychischer Zustand: виснажений, ковідіот, коронапсихоз, скажаніти.

3) Körper: короножир.

4) Erholung, Entspannung, Sport: zoоm-вечірка, zоот-концерт, онлайн-вистава, онлайн-тренування.

5) Mode: захисний, zоom-етикет.

3 Soziales Leben:

1) Alltagsleben/Proteste: послаблення, протестувальник, протест.

2) Beschränkungen/Warnsysteme: адаптивний, спецрейс, зонування.

3) Berufswelt: дистанційка, ковід-бізнесмен, соціальний, підтримка, спецперепустка.

4) Ausbildung: дистанційний, змішаний, онлайн-заняття, онлайн-конференція, онлайн-курс, онлайн-урок, zоom, zоот-заняття.

5) Medien: Вайбер-спільнота, інфодемія, інформагенція, онлайн-брифінг, Телеграм-канал, соцмережа, Фейсбук-сторінка.

6) Politik, Institutionen, Gremien: ВООЗ (Всесвітня організація охорони здоров'я), Мінцифри, МОЗ (Міністерство охорони здоров“я), РНБО (Рада Національної Безпеки України).

Nach grammatischen Kategorien können die Coronapandemie-Wörter in vier Wortarten eingeteilt werden, die zu unterschiedlichen Wortbildungstypen gehören und sowohl primäre als auch sekundäre sprachliche Nominationen sind.

A. Substantive. Substantive bilden mit 48,5\% die größte Gruppe. In der Gruppe werden einfache Substantive (14 \%), Zusammensetzungen (15,3\%) explizite Derivate (15\%), Konvertierungen (0,4 \%) und Kurzwortbildungen (3,8 \%) unterschieden.

1 Die Anzahl der einfachen Substantive ist auch nicht groß wie im Deutschen, etwa 14 \%. Einige sind Entlehnungen, andere sind typisch ukrainisch. Sie sind sowohl primäre als auch sekundäre Nominationen, u. a. konzeptuelle Metaphern sind vorhanden: вакцина (lat.) 'виготовлений із штучно ослаблених або вбитих мікробів, збудників інфекційних хвороб препарат, що вводиться в організм людини та тварини для попередження хвороб і частково для їх лікування’ (Impfstoff); Zoom (engl.) ‘платформа для проведення відеоконференцій'; випадок 'те, що сталося, трапилося (звичайно несподівано)' (Fall) (SUM, 2020).

Als Beispiel der konzeptuellen Metapher KRANKHEIT IST KURZFRISTIGE STRAHLUNG wird das Substantiv cпалax 'раптове виникнення, а також інтенсивний розвиток чого-небудь (Ausbruch)' eingeführt (SUM, 2020).

2 Zusammensetzungen bilden 15,3 \% des Materials. Zu betonen ist, dass folgende Konstituenten in den nominalen Zusammensetzungen am häufigsten vertreten sind: онлайн (3 \%), корона (1,5%), zоom (1,4\%). In dieser Gruppe werden unterschieden:

1) zweiteilige Determinativkomposita (11\%) (ukrainische, entlehnte Komposita oder Komposita mit entlehnten Konstituenten), primäre Nominationen: Nomen-Nomen-Komposita ohne Fugenelement: онлайн-брифінг ‘короткий публічний виступ міністра охорони здоров'я в інтернеті в режимі реального часу щодо поточного стану із коронавірусом' (Coronabriefing); коронакриза 'економічна, соціальна і культурна криза, викликана реакцією урядів на пандемію коронавірусу, а саме майже повним припиненням економічної, соціальної та культурної активності' (Coronakrise); zoom-заняття 'заняття, що проводиться за допомогою платформи Zoom' (Zoom-Unterricht); Pronomen-Nomen-Komposita mit Fugenelement: самоізоляція 'форма фізичного дистанціювання і зазвичай стосується людей, які ізолюються самостійно, бо належать до групи підвищеного ризику, яка вразлива до інфекції (Selbstisolation) (MGSY, 2020; SEK, 2020). 
Zu dieser Gruppe gehören auch Komposita, die als eine Konstituente verschiedene Typen von Kurzwörtern haben:

a) Kopfwörter (4\%), die meistens als erste Konstituente im Ukrainischen verwendet werden: мед(ичний) працівник 'особа, яка належить до медичного персоналу в лікувальних закладах' (Mitarbeiter der Klinik); спец(іальна)перепустка 'спеціальна перепустка для користування транспортом у червоній зоні карантину, вільному пересуванню містом, напр., для медичних працівників, поліцейських' (Sondererlaubnis für Verkehrsmitteln und freie Bewegung in der Stadt während der Quarantäne) (MGSU, 2020).

b) Buchstabenwörter (3\%), die überwiegend Initialwörter sind: ПРЛ (полімеразна ланцюгова реакція) -тест 'більш детальні аналізи, які проводять лише у вірусологічних лабораторіях зі спеціальним обладнанням методом полімеразної ланцюгової реакції' (PCR-Test); IФА (імуноферментний аналіз)тест 'імунологічний метод для визначення наявності певних антигенів, шляхом реакції антигенантитіло' (Covid-19-Antikörpertest) (SEK, 2020).

2) Kontaminate (4,3\%), bei denen wie im Deutschen morphologisch zwei Typen unterschieden werden: 1) metaphorische Komposita, deren Einheiten gemeinsame Laut/Buchstabenfolgen haben und die sich genau darin überschneiden: ковідіот (Ковід + ідіот) '1. людина, яка вперто ігнорує протокол 'соціального дистанціювання', тим самим сприяє поширенню Covid-19; 2. людина, яка запасається бакалійними товарами, чим надмірно розганяє страхи через Covid-19 і позбавляє інших життєвих ресурсів' (Соvidiot) (KRANKHEIT (CORONAVIRUS) MACHT DUMM); 2) Komposita, deren Konstituenten keine gemeinsamen Lautfolgen haben und daher nach Kriterien der Aussprechbarkeit ineinandergeschoben werden: інфодемія (інформація + пандемія) 'масове поширення інформаційного сміття відносно коронавірусу (Infodemie) (INFORMATION VERBREITET SICH RASCH UND MASSENHAFT); карантьє (карантин + рантьє) 'людина, яка здає в оренду домашніх тварин для прогулянок під час карантину' (Quarantier aus Quarantäne + Rentier. Mensch, der Haustiere für Spaziergänge ausleiht) (QUARANTÄNE IST DIE ZEIT FÜRS GELDVERDIENEN) (MS, 2020).

3 Explizite Derivate werden in suffixale (10 \%) und präfixale (5\%) Derivate geteilt.

1) Zu suffixalen Derivaten gehören Substantive mit ukrainischen Suffixen -енята $(0,4 \%),-\kappa a(2,5 \%),-\kappa о ~(0,4 \%)$, -ння (3,5 \%) oder mit entlehnten Suffixen -іал (0,7 \%), -ація (2,5\%), die primäre oder sekundäre Nominationen sind: дистанційка 'дистанційне навчання' (Distanzunterricht) (LERNEN KANN AUF DISTANZ STATTFINDEN); ковіденята 'діти, зачаті протягом пандемії коронавірусу та карантину' (Coronababies); ковідько 'ковідіот' (Covidiot) (KRANKHEIT (CORONAVIRUS) MACHT DUMM); короніал 'людина, зачата під час карантину' (Coronial); обстеження 'з“ясовування загального стану здоров'я, характеру захворювання' (Gesundheitsuntersuchung) (MS, 2020); госпіталізація 'поміщати хворого в лікарню, у госпіталь для лікування' (Aufnahme ins Krankenhaus) (SEK, 2020).

2) Präfixale Derivate werden meistens mit den Fremdpräfixen анти- (0,6\%), pe- (0,4\%), супер- (0,4\%) von expliziten ukrainischen Derivaten gebildet: антисептик 'гігієнічний засіб, яким обробляють руки, інші відкриті ділянки тіла, телефони, клавіатуру комп'ютерів, робочі поверхні, щоб знищити можливий вірус на них’; реінфікування 'повторне зараження організму тим самим мікробом' (Zweitinfektion).

In der Gruppe kommt auch die konzeptuelle Metapher MENSCH IST EIN GERÄT vor, die mit dem Wort суперпоширювач 'носій вірусу, який може заражати багато людей. В Україні 'суперпоширювачами' можуть бути водії маршруток, продавці, медики, священики та активні прихожани церков' (SEK, 2020) repräsentiert wird.

3 Konvertierungen. Als Ausgangspunkt dient das Substantiv хворий, das vom Adjektiv abgeleitet wird: хворий 'який має яку-небудь хворобу, нездужає; нездоровий' (der Kranke) (SUM, 2020). Das Lexem bildet 0,4 \% des Gesamtmaterials.

4 Der Anteil der Wortkürzungen beträgt 3,8 \%. Zu dieser Gruppe gehören Akronyme/Initialwörter: MO3 (Міністерство охорони здоров'я (Ministerium für Gesundheitsschutz der Ukraine)), ВООЗ (Всесвітня організація охорони здоров'я (WHO)), ШВЛ (штучна вентиляція легень (Lungenventilation)).

B. Mit $27 \%$ bilden die Adjektive die zweitgrößte Gruppe des Belegmaterials. Sie werden in zwei Gruppen geteilt: Zusammensetzungen (1\%) und explizite Derivate (19\%). 
1 Zusammensetzungen sind Nomen-Adjektiv-Komposita (1 \%), primäre Nominationen, u. а. коронавірусний ‘інфікований коронавірусом' (an Coronaviris infiziert) (MS, 2020; ST, 2020).

2 Explizite Derivate erscheinen als präfixale (12\%) und suffixale (7\%) als primäre Nominationen.

1) präfixale Derivate (14 \%) werden vor allem mit den ukrainischen Präfixen без- (1,8\%), проти- (3,2\%), gebildet: безконтактний 'не торкаючись тіла людини' (kontaktlos); протиепідимічний 'для боротьби з епідемією, для запобігання їй' (antiepidem isch) (SUM, 2020).

2) suffixale Derivate (12\%) werden meistens mit den ukrainischen Suffixen -ійн(ий) (3,3 \%), -альн(ий) (2,8\%) gebildet: дистанційний ‘який здійснюється або діє на певній віддалі, дистанції (auf Distanz); летальний 'смертельний' (letal) (SUM, 2020).

C. Partizipien sind explizite Derivate, primäre Nominationen, bilden etwa 9,5\% und erscheinen als präfixale und suffixale Derivate.

1) präfixale Derivate (4 \%) werden mit den ukrainischen Präfixen про- $(5,75 \%)$, пере- $(3,5 \%)$ am häufigsten gebildet: протестований 'той, кому зробили тест на (антитіла, або ПРЛ-тест)' (die getestete Person) (SUM, 2020).

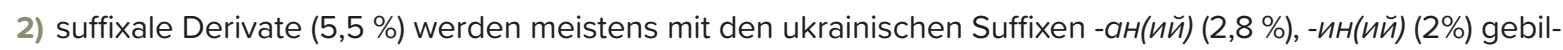
det: інфікований 'той, хто захворів на (коронавірус)' (der Infizierte)' (SUM, 2020).

D. Verben. Die untersuchten Verben sind Komposita, primäre Nominationen $(0,4 \%)$ oder explizite, suffixale Derivate $(14,6 \%)$.

1) Komposita $(0,4 \%)$ sind wie im Deutschen als Nomen-Verb-Komposita vertreten: відеочатитися 'комунікувати один з одним за допомогою відеочата' (videochatten) (MS, 2020).

2) Suffixale Derivate (14,6\%) werden vom Stammwort vor allem mit den ukrainischen Suffixen -at( $(4)(4,5 \%)$, -и/iт(и) (3,5 \%), -уват(и) (2,5 \%) etc. gebildet: каратинувати 'перебувати карантин у режимі самоізоляції' (in Selbstquarantäne sein); коронувати ‘хворіти на коронавірус, заразити когось коронавірусом' (ат Coronavirus krank sein, jnd. mit dem Coronavirus infizieren) (MS, 2020).

Die Studie des Coronapandemie-Wortschatzes zeigt, dass 23 \% des untersuchten Materials Neologismen sind. Diese Neologismen lassen sich in folgende Typen unterteilen:

1 Neubildungen oder Neulexeme (22\%), die meistens entlehnt sind: локдаун (engl. Entlehnung) 'обов'язкове розпорядження влади про те, щоб жителі певного міста, регіону або іншої частини території країни залишалися у своїх домівках, щоб уникнути розповсюдження інфекції' (Lockdown); санітайзер (engl. Entlehnung) 'гігієнічний засіб, яким обробляють руки, інші відкриті ділянки тіла, телефони, клавіатуру комп'ютерів, робочі поверхні, щоб знищити можливий вірус на них' (Hygienmittel); скажаніти 'потерпати від вимушеної соціальної ізоляції внаслідок коронавірусу' (Coronablues) (ST, 2020; MS, 2020).

2 Neubedeutung (1\%) oder eine kodifizierte Form mit einer neuen Bedeutung. Als Beispiel können zwei ukrainische Wörter angeführt werden: антирекорд 'найвищий показник' (auf höchstem Stand). Eigentlich repräsentiert dieses Benennungseinheit den Gegensatz, weil es buchstäblich 'auf niedrigstem Stand' bedeutet, aber wird gegenwärtig für die Bezeichnung des höchsten Standes der COVID-Neuinfektionen in der Ukraine verwendet; зонування, ursprünglich bezeichnete das Wort 'спосіб забезпечення використання земель для різних суспільних потреб' (SUM, 2020) (zonieren), jetzt repräsentiert es 'розподіл території України на зони (зелена, жовта, помаранчева, червона) в залежності від рівня захворюваності на ковід' (Соrоnaampel, Coronaampelsystem).

Im Coronapandemie-Wortschatz lassen sich Termini aus dem Medizinbereich feststellen, die in folgende Sachgruppen eingeteilt werden können:

1 Krankheit und Symptome: ковід, реінфікування, COVID-19, Sars-CoV-2.

2 Methoden der Eindämmung des Virus: зонування, обсервація, самоізоляція.

3 Tests: ІФА-тест, ПРЛ-тест, скринінг, тампон-метод.

4 Infizierte und nicht-infizierte Personen: інфікований.

5 Ausbreitung und Behandlung: суперпоширювач. 
Zur kontrastierenden Beschreibung des CoronapandemieWortschatzes in beiden Sprachen
Im Ergebnis der kontrastiven Materialanalyse der deutschen und ukrainischen Belege lässt sich feststellen, dass der deutsche Coronapandemie-Wortschatz reicher, bildhafter und verschiedenartiger im Gegensatz zum ukrainischen ist. Die unterschiedliche Anzahl im Untersuchungsmaterial lässt sich unseres Erachtens u. a. durch folgende Merkmale erklären: 1) die meisten Wörter sind im deutschen Coronapandemie-Wortschatz Zusammensetzungen, im Ukrainischen dagegen ist es eher eine Ausnahme, etwas mit einem Kompositum zu bezeichnen. Typisch ukrainisch ist die Benennung durch eine Wortgruppe, die aber nicht Gegenstand dieser Studie ist; 2) die CoronaPandemie ist für die Ukrainer nicht superaktuell, sie sind eher coronaskeptisch, weil Corona kein großes Problem im Gegensatz zum Krieg in der Ost-Ukraine, zu den finanziellen Problemen, zur politischer Instabilität ist.

Die festgestellten Sachgruppen werden unterschiedlich versprachlicht, sekundäre Nominationen (konzeptuelle Metaphern/Metonymien) sind ebenfalls unterschiedlich vertreten. Entlehntes Wortgut, vor allem aus dem Englischen, ist mehrfach im Deutschen vertreten. Aus der Sicht des Sprachwandels lassen sich im Deutschen quantitativ häufiger Neologismen finden. Die Anzahl der medizinischen Termini ist fast gleich, was damit zu erklären ist, dass medizinische Termini griechischer bzw. lateinischer Herkunft und in vielen Sprachen gleich sind (s. Tabelle 1).

Tabelle 1 Sachgruppen im Coronapandemie-Wortschatz: Nomination, Sprachwandel, Terminologie

\begin{tabular}{|c|c|c|c|c|c|}
\hline \multicolumn{4}{|c|}{ Coronapandemie-Wortschatz } & $\begin{array}{l}\text { DEUTSCH } \\
735 \text { Wörter }\end{array}$ & $\begin{array}{l}\text { UKRAINISCH } \\
235 \text { Wörter }\end{array}$ \\
\hline \multirow{17}{*}{ Sachgruppen } & \multirow{4}{*}{ 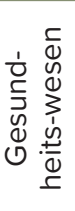 } & \multicolumn{2}{|r|}{ Krankheit } & 51 & 14 \\
\hline & & \multicolumn{2}{|c|}{ Schutz und Schutzmaßnahmen } & 171 & 48 \\
\hline & & \multicolumn{2}{|c|}{ infizierte Personen } & 17 & 15 \\
\hline & & \multicolumn{2}{|r|}{ Zeit } & 22 & 2 \\
\hline & \multirow{7}{*}{$\begin{array}{l}\frac{c}{U} \\
\mathcal{N} \\
\frac{C}{D} \\
\sum\end{array}$} & \multirow{2}{*}{$\begin{array}{l}\text { Personen-bezeich- } \\
\text { nungen }\end{array}$} & $\begin{array}{l}\text { nicht-infizierte } \\
\text { Personen }\end{array}$ & 15 & 7 \\
\hline & & & $\begin{array}{l}\text { Personen, die nicht an das Corona- } \\
\text { virus glauben }\end{array}$ & 13 & 2 \\
\hline & & \multicolumn{2}{|c|}{ Emotionaler und psychischer Zustand } & 31 & 5 \\
\hline & & \multicolumn{2}{|r|}{ Körper } & 17 & 1 \\
\hline & & \multicolumn{2}{|c|}{ Erholung, Entspannung, Sport } & 52 & 42 \\
\hline & & \multicolumn{2}{|r|}{ Essen } & 7 & 0 \\
\hline & & \multicolumn{2}{|r|}{ Mode } & 17 & 3 \\
\hline & \multirow{6}{*}{$\begin{array}{l}\frac{c}{0} \\
0 \\
0 \\
\\
0 \\
\frac{0}{0} \\
\frac{0}{N} \\
0 \\
0\end{array}$} & \multicolumn{2}{|c|}{ Alltagsleben/Proteste } & 135 & 32 \\
\hline & & \multicolumn{2}{|c|}{ Beschränkungen/Warnsysteme } & 71 & 7 \\
\hline & & \multicolumn{2}{|r|}{ Berufswelt } & 50 & 18 \\
\hline & & \multicolumn{2}{|r|}{ Ausbildung } & 43 & 17 \\
\hline & & \multicolumn{2}{|r|}{ Medien } & 15 & 9 \\
\hline & & \multicolumn{2}{|c|}{ Politik, Institutionen, Gremien } & 8 & 13 \\
\hline \multirow{2}{*}{$\begin{array}{l}\text { sekundäre } \\
\text { Nominationen }\end{array}$} & \multicolumn{3}{|c|}{ konzeptuelle Metaphern } & 31 & 9 \\
\hline & \multicolumn{3}{|c|}{ konzeptuelle Metonymien } & 1 & 0 \\
\hline \multicolumn{4}{|l|}{ Entlehnungen } & 113 & 37 \\
\hline \multicolumn{4}{|l|}{ Neologismen } & 577 & 25 \\
\hline \multicolumn{4}{|c|}{ Medizinische Termini } & 40 & 35 \\
\hline
\end{tabular}


Die quantitative Analyse der Versprachlichungen je Sachgruppe lässt verstehen, dass die Anzahl der Benennungseinheiten die Wichtigkeit der Sachgruppe für den Sprachträger beweist: im Deutschen sind Schutz und Schutzmaßnahmen, Alltagsleben und Proteste gegen Beschränkungen wichtig, im Ukrainischen Schutz und Schutzmaßnahmen, Alltagsleben und Proteste, zusätzlich Erholung, Entspannung und Sport. Außerdem scheint es klar, dass die deutsche Sprache zur Neologismenbildung und zur Entlehnung tendiert.

Im analysierten Wortschatz sind die gleichen vier Wortarten in beiden Sprachen anzutreffen, wobei Stammwörter und Wortbildungsprodukte zu unterscheiden sind. Festzustellen ist, dass sich im Deutschen die Zusammensetzung im Gegensatz zum Ukrainischen quantitativ häufiger findet, d. h. im Deutschen ist es die produktivste Wortbildungsart (s. Tabelle 2).

Tabelle 2 Kontrastive Analyse des Coronapandemie-Wortschatzes nach Wortarten und Wortbildung

\begin{tabular}{c|c|c|c}
\multirow{2}{*}{ Coronapandemie-Wortschatz } & DEUTSCH 735 Wörter & UKRAINISCH 235 Wörter \\
\hline \multirow{4}{*}{ Wortarten } & Substantive & 632 & 114 \\
\cline { 2 - 4 } & Adjektive & 55 & 22 \\
\cline { 2 - 4 } & Partizipien & 26 & 35 \\
\hline \multirow{4}{*}{ Wortbildung } & Stammwörter & 22 & 33 \\
\cline { 2 - 4 } & Zusammensetzungen/ Kontaminate & 65 & $38 / 10$ \\
\cline { 2 - 4 } & präfixale Derivate & $524 / 10$ & 55 \\
\cline { 2 - 4 } & Suffixale Derivate & 68 & 99 \\
\cline { 2 - 4 } & Konvertierungen & 65 & 1 \\
\hline
\end{tabular}

Im Deutschen wie im Ukrainischen lassen sich auch im Hinblick auf die Wortarteneinteilung gewisse Parallelen aufzeigen. Am häufigsten sind Substantive in beiden Sprachen vertreten, Partizipien haben fast den gleichen Anteil am Belegmaterial. Im Bereich der Wortbildung ist im Deutschen die Zusammensetzung am produktivsten, im Ukrainischen die Suffigierung und Präfigierung. Konvertierungen kommen im Deutschen und im Ukrainischen kaum vor. Die Anzahl der Initialwörter ist fast gleich. Kurzwörter kommen als selbstständige Wörter oder Konstituenten von Komposita vor.

Zum Gegenstand der Kontrastierung aufgrund der Übereinstimmungen und Unterschiede werden insgesamt 180 Wortpaare. Dieser zahlenmäßige Unterschied ergibt sich daraus, dass sich nur bei den genannten 180 Paaren lexikalische Korrespondenzen zeigen, wohingegen im Belegmaterial zahlreiche Fälle von Divergenz auftreten.

Die Kontrastierung der Wortpaare ergibt drei Hauptäquivalenztypen: Voll- (29\%), Teil- (12 \%) und Nulläquivalenz (59\%). Zu betonen ist, dass die Äquivalenz als semantische Übereinstimmung sprachlicher Zeichen verstanden wird (Sternemann et al., 1983, S. 43-47), indem die Bedeutung der deutschen Benennungseinheiten zum Ausgangspunkt der Feststellung der Entsprechungen im Ukrainischen wird.

1 Volläquivalenz findet sich vor allem in solchen Wortpaaren, deren Wörter in beiden Sprachen Entlehnungen oder Termini sind: Lockdown - локдаун ('Zeitraum, in dem fast alle wirtschaftlichen und gesellschaftlichen Aktivitäten auf politische Anordnung hin stillgelegt sind (z. B. zum Infektionsschutz)'); PCR-Test - ПРЛ-тест ('medizinisches Untersuchungsverfahren zur Feststellung einer Virusinfektion, bei dem mithilfe von Abstrichen aus Mund-, Nasen- und Rachenraum auf virales Erbgut eines Erregers getestet wird'); Selbstquarantäne - самоізоляція ('Schutzmaßnahme gegen die Verbreitung einer Krankheit, bei der Personen, die von einer ansteckenden Krankheit befallen sind oder bei denen Verdacht darauf besteht, sich freiwillig vorübergehend im eigenen Haushalt isolieren'). 
Es gibt auch volläquivalente Benennungseinheiten, die aus einheimischen Sprachmitteln gebildet werden: Corönchen - ковідка ((verharmlosend für) das Coronavirus in beiden Sprachen); Coronaspeck - коронажир ('durch Bewegungsmangel, Langeweile, Stress usw. während der COVID-19-Pandemie angegessenes Fettgewebe'). Festzustellen ist, dass diese Paare sogar semantisch-formale Übereinstimmungen aufweisen: im ersten Paar werden in beiden Sprachen Diminutivsuffixe -chen und -ka gebraucht, im zweiten Paar sind beide Wörter Komposita aus gleichen Konstituenten Corona (корона) und Speck (жир).

2 Teiläquivalenz zeigt sich in folgenden Wortpaaren: Covidiot - ковідіот (im Ukrainischen bedeutet dieses Wort nicht nur eine Person, die sich während der COVID-19-Pandemie unangemessen verhält, sondern auch eine Person, die sich mit dem Einkauf großer Mengen von Waren des täglichen Bedarfs, besonders von Lebensmitteln, zur Schaffung eines Vorrats beschäftigt, was im Deutschen mit Hamsterkauf repräsentiert wird); overzoomed - зумбі (im Deutschen werden so Leute bezeichnet, die durch zu viele Videokonferenzen (mit der Software Zoom $^{\circledR}$ ) gestresst werden, im Ukrainischen werden mit dieser Benennungseinheit Menschen bezeichnet, die zu viel Zeit mit der Videokonferenz Zoom verbringen).

3 Nulläquivalenz ist im Untersuchungsmaterial am häufigsten vertreten, weil der deutsche CoronapandemieWortschatz reich an bildhaften Neubildungen ist. Als Benennungseinheiten mit Nulläquivalenz gelten deutsche Wörter, die einen psychischen Zustand bezeichnen, weil diese Begriffe im Ukrainischen bis jetzt auch nicht mit Wortgruppen repräsentiert werden: Zoomfatigue 'tiefe (geistige und körperliche) Erschöpfung aufgrund von zu vielen und zu langen Videokonferenzen'; Coronahysterie 'durch die Angst vor einer Anstekkung mit dem Coronavirus SARS-CoV-19 und wegen der Auswirkungen der COVID-19-Pandemie ausgelöste allgemeine (nervöse) Aufgeregtheit'; Touristenphobie 'Angst der ortsansässigen Bevölkerung vor (zu) vielen Urlaubern im eigenen Land' (NWB, 2020).

Im Hinblick auf die Semantik kommt auch Divergenz vor, d. h. eine Einheit einer Sprache verfügt über mehrere Einheiten in einer anderen Sprache (Sternin, 2006, S. 23). In unserem Fall ist die Rede von mehreren deutschen Entsprechungen für ein ukrainisches Wort. Als Belege führen wir die kontrastierten Wörter an, die uns besonders beeindruckt haben: коронадисидент - 1. Aluhut, 2. Coronaleugner, 3. Coronaskeptiker, 4. Coronasünder, 5. Maskenmuffel, 6. Maskenverweigerer. Diese Divergenz zeigt, dass das Thema der Verschwörungstheorie eine gewisse Rolle in der deutschen Gesellschaft spielt. Die Anhänger der Verschwörungstheorie sind sicher, dass die Coronavirus-Maßnahmen nur ein Ziel hätten, und zwar die Abschaffung der Demokratie; демонстрація - 1. Anticoronademo, 2. Anticoronademonstration, 3. Anticoronaprotest, 4. Coronademo, 5. Coronademonstration, 6. Coronaprotest, 7. Hygiendemo. Die Anzahl der Wörter im Deutschen ist ein Signal dafür, dass Teile der deutschen Gesellschaft schon coronamüde sind und regelmäßig gegen die Corona-Politik der BRD-Regierung demonstrieren. In der Ukraine ist es noch eher eine Ausnahme; мacka - 1. Alltagsmaske, 2. Behelfsmaske, 3. Behelfsmundnasenschutz, 4. Behelfmundschutz, 5. Communitymaske, 6. Designermaske, 7. Designermundschutz, 8. Munaschu, 9. Munaske, 10. Mund-Nasen-Bedeckung, 11. Mund-Nasen-Schutz, 12. Mund-Nasen-Schutz-Maske, 13. Volksmaske. Das ukrainische Lexem маска hat 13 deutsche Teiläquivalente, was die Kreativität der deutschen Muttersprachler noch einmal beweist, wobei wichtige Merkmale des Gegenstandes Maske sprachlich klar und präzis repräsentiert werden soll.

Fazit und

Die vorliegende Studie lässt sich in eine Reihe kontrastiver Untersuchungen zum SprachenAusblick paar Deutsch - Ukrainisch einordnen. In der Studie wurde der Versuch unternommen, Benennungseinheiten der Coronapandemie-Zeit, die im Gegenwartsdeutschen und Gegenwartsukrainischen häufig verwendet werden, zu analysieren. Von entscheidender Bedeutung war dabei die Tatsache, dass die Anzahl der analysierten Wörter in beiden Sprachen variiert. Was im Deutschen mit Wörtern versprachlicht wird, kann im Ukrainischen oft nur mit Wortgruppen zum Ausdruck gebracht werden, die jedoch in dieser Studie nicht thematisiert wurden. Die Belege wurden in Sachgruppen gruppiert, ihre Struktur, Semantik, Wortbildung und Herkunft intralingual untersucht. Die wesentlichen Unterschiede wurden in den Bereichen der sprachlichen Repräsentationen, der Wortbildung und der Bildung der Neuwörter festgestellt. Anhand des Belegmaterials konnte ermittelt werden, dass die Anzahl der Entlehnungen in beiden Sprachen variiert. Außerdem wurden konzeptuelle Metaphern und Metonymien ermittelt. Die Kontrastierung der deutsch-ukrainischen Wortpaare aufgrund der Übereinstimmungen und Unterschiede führte zu den drei 
Hauptäquivalenztypen Voll-, Teil- und Nulläquivalenz. Ebenso wurden Divergenzen festgestellt, wonach einem ukrainischen Wort mehrere deutsche Benennungseinheiten entsprechen.

Offen bleiben musste die kontrastive Analyse von Kollokationen und Phraseologismen, die sicher im Coronapandemie-Wortschatz in beiden Sprachen vorhanden sind. In diesem Zusammenhang wäre es erwünscht, diese sprachlichen Einheiten auch im Rahmen der Diskurslinguistik zu untersuchen.

Kurzwörter

BMG - Bundesministerium für Gesundheit.

DWDS - Digitales Wörterbuch der deutschen Sprache

MS - Myslovo

MGSU - Ministerium für Gesundheitsschutz der Ukraine

NWB - Neologismenwörterbuch. Neuer Wort- schatz rund um die Coronapandemie

SEK - Slovnyk epokhy koronavirusu

ST - Slovnyk terminiv, yaki potribno znaty pid chas pandemiyi

SUM - Slovnyk ukrainskoi movy

WHO - Weltgesundheitsorganisation. Regionalbüro für Europa.

\section{Literaturverzeichnis}

1 Chrissou, M. (2001). Kontrastive Untersuchungen zu deutschen und neugriechischen Phraseologismen mit animalistischer Lexik. Hessen, Clemon-Verlag.

2 Dobrovol'skij, D. (2018). Phraseme aus kognitiver und kontrastiver Sicht. In Engelberg, S., Kämper , H. \& Storjohann, P. (Hrsg.), Wortschatz: Theorie, Empirie, Dokumentation (S. 151-170). Berlin: Walter de Gruyter. https://doi. org/10.1515/9783110538588-007

3 Donalies, E. (2005). Wortbildung des Deutschen. Ein Überblick (2. überarb. Auflage). Tübingen: Narr Verlag.

4 Gudavičius A. (1985). Sopostavitel'naja semasiologija litovskogo i russkogo jazykov [Contrastive Semasiology of Litainian and Russian]. Vil'njus: Mokslas. (In Russian).

5 Hagen, A. (2018). Verschmelzung von Präposition und Artikel. Eine kontrastive Analyse zum Deutschen und Italienischen (Konvergenz und Divirgenz, 6). Berlin/Boston, de Gruyter. https://doi. org/10.1515/9783110557862.

6 Helbig, G. (1976). Zur Rolle des kontrastiven Sprachvergleichs für den Fremdsprachenunterricht (Möglichkeiten, Voraussetzungen, Grenzen). Deutsch als Fremdsprache, Heft. 1, 9-16.

7 Hnatiuk, L. (2017). The Functional and Pragmatic Peculiarities of the Anthropocentric Phraseological Units in Different Languages and Cultural Environments (on the Descriptive Material of Ukrainian, Russian, Polish, English). Kalbų studijos / Studies about languages, 30, 1828. https://doi.org/10.5755/j01.sal.0.30.17724.

8 Klosa-Kückelhaus, A. (2020). Medizinisches Vokabular rund um die Coronapandemie. https://www1.ids-mannheim.de/fileadmin/ aktuell/Coronakrise/Klosa_medizinisches_ Vokabular.pdf (Accessed August 2020).

9 Klosa-Kückelhaus, A. (2020a). Neue Wörter in der Coronakrise - von Social Distancing und Gabenzaun. Sprachreport, 2, 6-8.

10 König, E., \& Nekula, M. (2013). Zum Verhältnis von Kontrastiver Linguistik und Sprachtypologie: Präpositionen im Vergleich. Bilingualer Sprachvergleich und Typologie: Deutsch - Tschechisch. Tübingen: Stauffenburg/Julius Groos. (= IDS-Reihe Deutsch im Kontrast 28) (pp. 1546) ISBN: 978-3-87276-893-3.

11 Kovbasyuk, L. A. (2019). Neofitsiyni oykonimy suchasnoyi nimetskoyi movy $\vee$ mizhkulturniy komunikatsiy. [Unofficial Oikonyms of Modern German in Intercultural Communication]. Naukovyy visnyk KHDU Seriya Hermanistyka ta mizhkul'turna komunikatsiya, 1, 291$296 . \quad$ https://doi.org/10.32999/ksu26633426/2019-1-45. (In Ukranian).

12 Lutzeier. P. R. (1995). Es lohnt sich Kontrastive Lexikologie Deutsch/Englisch im Bereich «Einkünfte». In Kromann, H.-P. 
\& Kjær, A. L. (Hrsg.), Von der Allgegenwart der Lexikologie. Kontrastive Lexikologie als Vorstufe zur zweisprachigen Lexikographie (S. 7-19). Tübingen: Niemeyer, https://doi. org/10.1515/9783110938081.7

13 Mizin, K., \& Ovsiienko, L. (2020). The German Linguo-cultural Concept SCHADENFREUDE in Cross-cultural Perspective: a Corpus-based Approach. Lege Artis. Language yesterday, today, tomorrow, 1, 143-184. ISSN 2453-8035.

14 Möhrs, Ch. (2020). Systemrelevant - eine sprachwissenschaftliche Betrachtung des Begriffs aus aktuellem Anlass. Sprachreport, 2, 6-8.

15 Pohl, I., \& Kaczmarek, H. (2014). Kontrastive Analyse des phraseologischen Vokabulars zur Emotion ANGST im Deutschen und Polnischen. In Gwozdzia, G. \& Sznurkowskiego, P. (Podred.), Studia Neofilologiczne X. (S. 145171). Czestochowa: AJD. http://dlibra.bg.ajd. czest.pl:8080/Content/2105/11.pdf

16 Pryimak, D. (2019). Exotic Plural Forms of Foreign Currency Names in English, French, Italian und Ukrainian: grammatical and Lexicographical perspectives. Kalbų studijos / Studies about languages, 35, 5-20. https:// doi.org/10.5755/j01.sal.0.35.21962.

Kurzwörter
1 Bilodid, I. K. (ed.). (1970-1980). Slovnyk ukrainskoi movy [Dictionary of the Ukrainian Language], V. 1-11. Kyiv: Naukova dumka. http://sum.in.ua/ (Accessed August 2020). (In Ukrainian).

2 Bundesministerium für Gesundheit. (2020). Coronavirus SARS-CoV-2: Chronik der bisherigen Maßnahmen. https:// www.bundesgesundheitsministerium. de/coronavirus/chronik-coronavirus.html (Accessed July 2020).

3 Digitales Wörterbuch der deutschen Sprache. https://dwds.de. (Accessed August 2020).

4 Ministeriums für Gesundheitsschutz der Ukraine. https://moz.gov.ua/koronavirus2019-ncov (Accessed August 2020).

5 Myslovo. [Dictionary you write]. http:// myslovo.com. (Accessed August 2020).

6 Neologismenwörterbuch. Neuer Wortschatz
17 Slavova, L., Borysenko, N., \& Kodubovska, O. (2020). The Evolution of Etymons Denoting an Inhabited Place in Ukrainian and English. Kalbų studijos / Studies about Languages, 36, 5669. https://doi.org/10.5755/j01.sal.0.36.24341.

18 Sternemann, R. et al. (1983). Einführung in die konfrontative Linguistik. Leipzig: Enzyklopaedie.

19 Sternin, I.A. (2006). Kontrastivnaya lingvistika. Problemy teorii i metodiki issledovaniya [Contrastive Linguistics. Problems of The Theory and the Methods of Investigation]. M: AST: Vostok - Zapad. (in Russian).

20 Stutterheim, Ch. (2018). Kontrastive Analyse 2020: Neue Horizonte. In Wöllstein, A., Gallmann, P., Habermann, M., \& Krifka M. (Hrsg.), Grammatiktheorie und Empirie in der germanistischen Linguistik (pp. 281-308). Berlin: de Gruyter https://doi. org/10.1515/9783110490992-010.

21 Tekin, Ö. (2012). Grundlagen der Kontrastiven Linguistik in Theorie und Praxis. Tübingen: Stauffenburg.

rund um die Coronapandemie, 2020. https:// www.owid.de/docs/neo/listen/corona.jsp (Accessed August 2020).

7 Slovnyk epokhy koronavirusu: 20 terminiv, yaki zavzhdy nahaduvatymut pro vesnu-2020, 2020.[Dictionary of Coronavirus Era: 20 terms that remind you of the spring 2020]. https://www.bbc.com/ukrainian/ features-52212810 (Accessed August 2020).

8 Slovnyk terminiv, yaki potribno znaty pid chas pandemiyi [Dictionary of Terms that must be known during the pandemic], 2020. https:// www.radiosvoboda.org/a/koronavirusterminy-slovnyk/30520097.html (Accessed August 2020).

9 Weltgesundheitsorganisation. Regionalbüro für Europa. https://www.euro.who.int/ de/health-topics/health-emergencies/ coronavirus-covid-19/novel-coronavirus2019-ncov (Accessed July 2020). 
Santrauka

Larysa Kovbasyuk. Koronaviruso žodynas šiuolaikinėse vokiečių ir ukrainiečių kalbose.

Straipsnis atskleidžia tyrimo, kurio metu buvo lyginamas koronaviruso pandemijos žodynas šiuolaikinèse vokiečių ir ukrainiečių kalbose, rezultatus. Tyrimo tikslas - ištirti žodžius, vartotus koronaviruso pandemijos metu Vokietijoje ir Ukrainoje, aprašyti pasirinktų žodžių abiejose kalbose struktūrinius ir semantinius požymius, atlikti konceptualią jų analizę, palyginti žodžių poras, nustatyti ir išanalizuoti ekvivalentụ tipus. Analize atlikta pasitelkiant rankiniu būdu surinktą tekstyną iš žodžių koronaviruso tema. Analizuotų kalbinių vienetų skaičius abiejose kalbose nevienodas, t. y. 735 žodžiai vokiečių kalba ir 235 žodžiai ukrainiečių kalba. Surinkti žodžiai suskirstyti ị temines grupes ir išanalizuoti pagal struktūrinius-semantinius požymius, taip pat išskirti abiejų kalbų žodžių darybos tipai. Analizuota medžiaga atskleidè, kad vedinių ir naujadarų skaičius skiriasi priklausomai nuo kalbos. Nustatytos ir išnagrinètos konceptualiosios metaforos ir metonimijos. Lyginant vokiečių ir ukrainiečių žodžių poras remiantis semantiniais kriterijais išskirti visiško, dalinio ir nulinio ekvivalentiškumo atvejai.

\section{Summary}

\section{Larysa Kovbasyuk. Coronovirus Vocabulary in Modern German and Modern Ukrainian}

This article represents the results of a contrastive research on the coronavirus pandemic vocabulary of Modern German and Modern Ukrainian. The article aims at presenting words used during the coronavirus pandemic in Germany and Ukraine, describing structural and semantic features of selected words in both languages. The conceptual analysis is carried out, the word pairs are contrasted, and the existing types of equivalence are determined and examined. A corpus of manually compiled vocabulary (German: 735 words; Ukrainian: 235 words) was built. The empirical description shows that the number of analyzed units varies according to the language. The collected words were divided according to subject groups, which are represented quantitatively differently. The structural and semantic characteristics of the analyzed units are described. The word-formation types in both languages are presented precisely. Based on the examined material, it can be stated that the number of borrowings and neologisms in both languages is different. Conceptual metaphor and metonymy are determined and discussed. The contrasting of the German-Ukrainian word pairs according to the semantic criteria demonstrated full, partial, and zero equivalence.

\section{About the Author}

\section{LARYSA KOVBASYUK}

Candidate of Sc. in Philology, Associate Professor at Department of Germanic and Romanic Languages at Kherson State University, Ukraine

\section{Research interests \\ Phraseology, Cognitive Linguistics, Contrastive Linguistics, Intercultural Communication, Corpus Linguistics.}

\section{Address}

Kherson State University, vul. Universytetska, 27, Kherson, Ukraine

E-mail kovlorik@gmail.com 